\title{
Perception of rhythmic grouping: Testing the iambic/trochaic law
}

\author{
Jessica S. F. HaY and Randy L. Diehl \\ University of Texas, Austin, Texas
}

\begin{abstract}
This study was designed to test the iambic/trochaic law, which claims that elements contrasting in duration naturally form rhythmic groupings with final prominence, whereas elements contrasting in intensity form groupings with initial prominence. It was also designed to evaluate whether the iambic/trochaic law describes general auditory biases, or whether rhythmic grouping is speech or language specific. In two experiments, listeners were presented with sequences of alternating /ga/ syllables or square wave segments that varied in either duration or intensity and were asked to indicate whether they heard a trochaic (i.e., strong-weak) or an iambic (i.e., weak-strong) rhythmic pattern. Experiment 1 provided a validation of the iambic/trochaic law in Englishspeaking listeners; for both speech and nonspeech stimuli, variations in duration resulted in iambic grouping, whereas variations in intensity resulted in trochaic grouping. In Experiment 2, no significant differences were found between the rhythmic-grouping performances of English- and French-speaking listeners. The speech/ nonspeech and cross-language parallels suggest that the perception of linguistic rhythm relies largely on general auditory mechanisms. The applicability of the iambic/trochaic law to speech segmentation is discussed.
\end{abstract}

In order to understand spoken language, listeners must be able to locate lexical items in continuous speech-a process that involves segmenting the speech stream. Although speech segmentation strategies may vary across languages, it has been hypothesized that segmentation tends to be based on linguistic rhythm (Cutler, 1994; Mattys, Jusczyk, Luce, \& Morgan, 1999).

Rhythm can generally be characterized as the repetition of patterned sequences of elements, often varying in prominence (Fraisse, 1974, 1982). This characterization applies most strictly to certain forms of music and poetry; however, normal speech also exhibits tendencies toward rhythmic patterning - for example, in the alternation of stressed and unstressed syllables. In addition, listeners may perceptually exaggerate the rhythmicity of utterances. For example, English-speaking listeners hear interstress intervals as more evenly spaced than they actually are (Darwin \& Donovan, 1980; Donovan \& Darwin, 1979; Lehiste, 1977).

How might perceived rhythm help listeners to group syllables into word or phrase length units or, equivalently, to detect word or phrase boundaries? One plausible answer is that in segmenting speech, listeners learn to exploit the typical rhythmic patterns of words or phrases in their native language (see, e.g., Cutler, 1994; Mattys et al., 1999). For example, French tends to be segmented by native listeners at the level of the syllable (Cutler, Mehler, Norris, \& Segui, 1986; Mehler, Dommergues, Frauenfelder, \& Segui, 1981), Japanese listeners rely on the mora for segmenting Japanese (Otake, Hatano, Cutler, \& Mehler,
1993), and English is most easily segmented by Anglophones, using a stress-based segmentation strategy (Cutler \& Butterfield, 1992; Cutler \& Norris, 1988; Echols, Crowhurst, \& Childers, 1997).

In most languages, words have fixed or, at least, characteristic stress patterns (Hyman, 1977), and these regularities are obviously informative about likely word boundaries. In word segmentation studies in which artificial languages are used, listeners are most successful when the phonological properties of the artificial language match those of their native language. For example, Vroomen, Tuomainen, and de Gelder (1998) found that the presence of word-initial stress, marked by pitch accent, facilitated word segmentation for native speakers of Finnish and Dutch, languages that have a predominance of word-initial stress. Word-initial stress did not help Frenchspeaking listeners segment the artificial language, possibly because stress rarely occurs on the first syllable of polysyllabic French words (Dell \& Vergnaud, 1984).

Research with infants further supports the idea that some effects of utterance rhythm on speech segmentation result from linguistic experience. Thiessen and Saffran (2003) exposed English-learning infants to an artificial language consisting of bisyllabic words with a typical English stress pattern (i.e., strong-weak, or trochaic), and found that 9-month-old infants, but not 6.5-month-old infants, used stress pattern as a cue to segmentation. When the artificial language consisted of words with a stress pattern less typical of English (i.e., weak-strong, or iambic), both 6.5- and 9-month-old infants missegmented the 
words and, instead, relied on the transition probabilities of the stimulus input for segmentation. By 9 months of age, infants appear to have learned some of the characteristic rhythmic patterns of their native language, and they can use this knowledge to help segment speech.

Another possible way that perceived rhythm may facilitate speech segmentation is via the operation of grouping biases that may exist independently of linguistic experience. Woodrow $(1909,1951)$ reported that for nonspeech sounds, trochaic rhythmic grouping (i.e., rhythm with group-initial prominence) is associated with variation in the relative loudness of the stimuli, whereas iambic rhythmic grouping (i.e., rhythm with group-final prominence) is associated with variation in the relative duration of the stimuli (see also Rice, 1992). Woodrow's findings formed the basis of the iambic/trochaic law (Hayes, 1995, p. 80), which states that (1) elements contrasting in intensity naturally form groupings with initial prominence and (2) elements contrasting in duration naturally form groupings with final prominence. Although iambs and trochees are metrical feet containing just two elements (weak-strong and strong-weak, respectively), the iambic/trochaic law is intended to apply to feet of greater than two elements as well - for example, dactyls (strong-weak-weak) and anapests (weak-weak-strong). In other words, what counts in the application of the iambic/trochaic law is whether a sequence is perceived as having initial versus final prominence.

Higher intensity and longer duration are correlates of lexically stressed syllables in English and other languages (Beckman, 1986; Delattre, 1965; Fry, 1955; Lehiste, 1970), and thus, the iambic/trochaic law may affect word segmentation in those languages. Fundamental frequency $(f 0)$ contour is also an important correlate of stressed syllables, but its detailed form tends to vary across linguistic contexts (Bolinger, 1958; Fry, 1958; Pierrehumbert, 1980). For this reason, and because the iambic/trochaic law makes no predictions about grouping based on $f 0$, this correlate will not be considered further in this study.

There is evidence that the iambic/trochaic law is relevant to speech segmentation. Cross-linguistically, wordand phrase-final syllables tend to be lengthened (Klatt, 1975, 1976; Lindblom \& Rapp, 1973; Oller, 1973), which, according to the law, should promote syllable grouping consistent with word and phrase boundaries. For example, Saffran, Newport, and Aslin (1996) showed that wordfinal lengthening helped English-speaking listeners segment new trisyllabic words from an artificial language but that word-initial lengthening did not. Although languagespecific learning may account for these results, they may also reflect the operation of the iambic/trochaic law.

Despite the growing literature on the effects of rhythm perception on speech segmentation, the manner in which the acoustic correlates of speech signals affect rhythmic grouping is not yet fully understood, and the rhythmic laws derived from Woodrow's (1909) studies have not, to our knowledge, been explicitly verified (but see Rice, 1992, and Woodrow, 1951, for a partial verification). The first aim of the present study was to provide a comprehensive and definitive test of the iambic/trochaic law.

The second aim of this study was to evaluate whether the iambic/trochaic law reflects general auditory biases, independently of language experience. In Experiments 1 and 2, we examined whether the law applies similarly to both speech and nonspeech stimuli, and in Experiment 2, we tested the law for two groups of participants with different native language backgrounds. The third aim was to consider whether the auditory biases implied by the iambic/trochaic law can actually be expected to facilitate the segmentation of natural utterances. This issue will be taken up in the General Discussion section.

\section{EXPERIMENT 1}

In this experiment, we tested the iambic/trochaic law with both speech and nonspeech stimulus sequences that alternated in either duration or intensity. A replication of Woodrow's (1909) study was warranted, given technological advances in stimulus construction and presentation since the early 20 th century. Woodrow himself noted some of these limitations of his 1909 study:

As a measure of the intensity of the sounds, the distance to which they were just audible was taken. It is not claimed that such a method of measurement is very exact, but on the whole it was considered the most satisfactory. The measurements were all made on the same day, ... in an open space left by the removal of an old building. (p. 14)

Woodrow (1909) additionally remarked that "the judgment concerning rhythm might be strongly influenced by which sound is heard first" (p. 23), but he claimed to have overcome this problem by instructing subjects to judge which rhythm was more "natural." Pilot studies in our lab were not as successful in overcoming this bias; whichever sound was heard first tended to be judged by listeners as the beginning of the rhythmic group.

In the present study, order of stimulus onset was counterbalanced, and stimulus onset was also masked. In addition, the construction and presentation of stimuli was performed with modern computer equipment. In accordance with the iambic/trochaic law, greater duration of one of the stimuli in each alternating pair was predicted to yield iambic grouping, whereas greater intensity of one of the stimuli in each alternating pair was predicted to yield trochaic grouping. Since Woodrow used only nonspeech sounds in his experiments, it is unclear whether the iambic/trochaic law applies similarly to speech and nonspeech. Claims regarding the applicability of the law to speech segmentation would presumably be weakened if the law did not apply similarly to the rhythmic grouping of speech sounds. Two groups of monolingual Englishspeaking listeners heard either sequences of alternating square wave segments or sequences of alternating synthetically produced syllables. If these speech and nonspeech tokens are processed using general auditory mechanisms, 
there should be no significant difference in the rhythmic grouping of these two types of stimuli.

\section{Method}

Listeners. Forty-eight native English-speaking listeners participated in Experiment 1 (24 in each of the speech and nonspeech conditions). All the participants were recruited from the introductory psychology participant pool at the University of Texas at Austin and were given credit toward partial fulfillment of course requirements. All reported being monolingual and having normal hearing. They were run in groups of 1-4.

Stimulus sequences. Sequences (11 sec in duration) were created by repeatedly alternating two stimuli (speech or nonspeech). The stimuli alternated in either duration or intensity, while the other dimension was held constant. In order to maintain consistency with previous studies (i.e., Rice, 1992; Woodrow, 1909), a 200-msec silent interval was inserted between all the stimuli in a sequence. Five duration-varying sequences were created in which the absolute difference between the alternating stimuli varied from $0 \mathrm{msec}$ (i.e., the same stimulus was repeated, forming a control sequence) to $100 \mathrm{msec}$ (i.e., a 200 -msec stimulus alternated with a $100-\mathrm{msec}$ stimulus), in 25 -msec steps. ${ }^{1}$ Five intensity-varying sequences were also created in which the absolute difference between the alternating stimuli varied from 0 to $12 \mathrm{~dB}$ (i.e., a 62-dB SPL stimulus alternated with a $50-\mathrm{dB}$ SPL stimulus), in 3-dB steps. Duration and intensity values were selected to fall within plausible ranges for natural productions (see Crystal \& House, 1990; Schwartz, Petinou, Goffman, Lazowski, \& Cartusciello, 1996). In this article, the nonalternating control sequence will be referred to as Control $D$ when it was presented in the context of duration-varying sequences and as Control I when presented in the context of intensity-varying sequences. Control sequences were included to provide a performance baseline with which the perception of the alternating sequences could be compared. The number of repetitions of each alternating pair of stimuli, within each 11 -sec sequence, varied from 14 to 16 as a function of the duration of the individual stimuli. Table 1 shows the acoustic parameters for the stimulus sequences in Experiment 1.

Nonspeech sequences. In the case of the nonspeech sequences, each stimulus consisted of a square wave segment that was created using an in-house signal-processing program (WAVAX) at a sampling rate of $10 \mathrm{kHz}$. The stimuli were then combined to form alternating sequences, as described above, using the same software.

Synthetic speech sequences. Synthetic speech sequences consisted of alternating tokens of the synthetic syllable /ga/. Each /ga/ token was created using the Klatt synthesizer (Klatt \& Klatt, 1990) at a sampling rate of $10 \mathrm{kHz}$. The first formant frequency had an onset value of $300 \mathrm{~Hz}$ and transitioned linearly over the first $55 \mathrm{msec}$ of the stimulus to its steady state value of $768 \mathrm{~Hz}$, during which time the first formant bandwidth (B1) was maintained at $60 \mathrm{~Hz}$. The second and third formant frequencies had onset values of 1840 and $1960 \mathrm{~Hz}$, respectively, and transitioned linearly over the first $55 \mathrm{msec}$ of the stimulus to reach their steady state values of 1333 and $2522 \mathrm{~Hz}$, respectively. The fourth and fifth formant frequencies remained constant at 3250 and $3700 \mathrm{~Hz}$, respectively. The bandwidths of the higher formants remained constant throughout the stimulus $(\mathrm{B} 2=90 \mathrm{~Hz}, \mathrm{~B} 3=150 \mathrm{~Hz}, \mathrm{~B} 4=200 \mathrm{~Hz}$, and B5 $=$ $200 \mathrm{~Hz}$ ). The $f 0$ remained constant at $100 \mathrm{~Hz}$. In order to mimic the release of the consonant, there was a $5-\mathrm{msec}$ burst at the onset of each token, which was created by adding $5 \mathrm{msec}$ of aspiration to the beginning of the signal, by increasing the bandwidth of the first formant to $1000 \mathrm{~Hz}$, and by eliminating voicing during this interval. The amplitude of the voiced portion of each stimulus was held constant until the last $10 \mathrm{msec}$ of the signal, at which point it decreased linearly to 0 .

Tokens of the syllable /ga/ had the same duration and intensity values as the corresponding square wave segments. Variations in duration were created by lengthening the steady state vowel portion of the syllable, but no change was made to the consonant portion. Vari-
Table 1

Acoustic Parameters for the Stimuli in Experiments 1 and 2

\begin{tabular}{lcccr}
\hline Set, Sequence & $\begin{array}{c}\text { Duration } \\
(\mathrm{msec})\end{array}$ & $\begin{array}{c}\text { Intensity } \\
(\mathrm{dB} \text { SPL })\end{array}$ & $\begin{array}{c}f 0 \\
(\mathrm{~Hz})\end{array}$ & $\begin{array}{r}\text { Absolute } \\
\text { Difference }\end{array}$ \\
\hline Duration, 1 & $200 \& 100$ & 56 & 100 & $100 \mathrm{msec}$ \\
Duration, 2 & $200 \& 125$ & 56 & 100 & $75 \mathrm{msec}$ \\
Duration, 3 & $200 \& 150$ & 56 & 100 & $50 \mathrm{msec}$ \\
Duration, 4 & $200 \& 175$ & 56 & 100 & $25 \mathrm{msec}$ \\
Control & $200 \& 200$ & 56 & 100 & $0 \mathrm{msec}$ \\
Intensity, 1 & 200 & $62 \& 50$ & 100 & $12 \mathrm{~dB}$ \\
Intensity, 2 & 200 & $62 \& 53$ & 100 & $9 \mathrm{~dB}$ \\
Intensity, 3 & 200 & $62 \& 56$ & 100 & $6 \mathrm{~dB}$ \\
Intensity, 4 & 200 & $62 \& 59$ & 100 & $3 \mathrm{~dB}$ \\
Control & 200 & $56 \& 56$ & 100 & $0 \mathrm{msec}$ \\
\hline
\end{tabular}

ations in intensity were made by matching the root-mean squared amplitude of a 200-msec syllable to that of the analogous square wave segment. Alternating syllable sequences were analogous in all other respects to the nonspeech sequences. The synthetic syllable was judged by the experimenters to be an unambiguous instance of $/ \mathrm{ga} /$.

Onset masking. In pilot studies, we observed a strong tendency for rhythmic judgments to be based on the pattern of the first two stimuli of the sequence. In order to reduce this effect, we took steps to mask the onset of the sequence. Order of stimulus sequence onset was counterbalanced, with half of the sequences starting with the longer or more intense stimulus and half starting with the shorter or less intense stimulus. Intensity was gradually increased according to a raised cosine function over the first $5 \mathrm{sec}$ of each 11 -sec sequence. During this same 5-sec interval, masking noise was presented with a gradually diminishing intensity, according to a raised cosine function. For the control sequence, there was a $-5.4-\mathrm{dB}$ signal-to-noise ratio during the $1 \mathrm{st} \mathrm{sec}$ of the 5 -sec masking interval.

There were no measures taken to mask the offset of the sequences, since they had little effect on judgments of rhythmicity during pilot studies. In this study, half of the sequences ended with the longer or more intense stimulus, and half ended with the shorter or less intense stimulus.

Procedure. The listeners were instructed to listen to each sequence and to group the alternating stimuli into a two-beat rhythmic pattern. They were told to indicate, by pressing a labeled button, whether the rhythm consisted of a strong sound followed by a weak sound or, alternatively, a weak sound followed by a strong sound. Stimulus sequences were presented in blocks according to the dimension of variation (i.e., duration or intensity varying). In the block that contained duration-varying stimuli, the five sequences had alternating stimuli with absolute duration differences of 100 , $75,50,25$, and $0 \mathrm{msec}$ (Control D), respectively. The absolute intensity differences were $12,9,6,3$, and $0 \mathrm{~dB}$ (Control I) for the five sequences of intensity-varying stimuli. Throughout the remainder of this article, the term magnitude of difference will be used to refer to the levels of absolute difference between alternating stimuli. Half of the sequences started with the stronger sound (i.e., longer or more intense), and the other half started with the weaker sound (i.e., shorter or less intense). Within each block, stimulus sequences were presented five times each in both possible orders of stimulus onset, ${ }^{2}$ for a total of 45 stimulus sequences per block. The order of stimulus sequence presentation was randomized within each block, and the order of the blocks was counterbalanced across listeners. At the beginning of each new block, the listeners were given 10 practice trials.

The listeners were seated at a response station in a double-walled sound-attenuated chamber. Stimulus presentation was controlled by an in-house experimental design program, implemented on a Gateway 2000 desktop computer, and the stimuli were presented through Beyer dynamic DT100 headphones at the specified decibel level. 


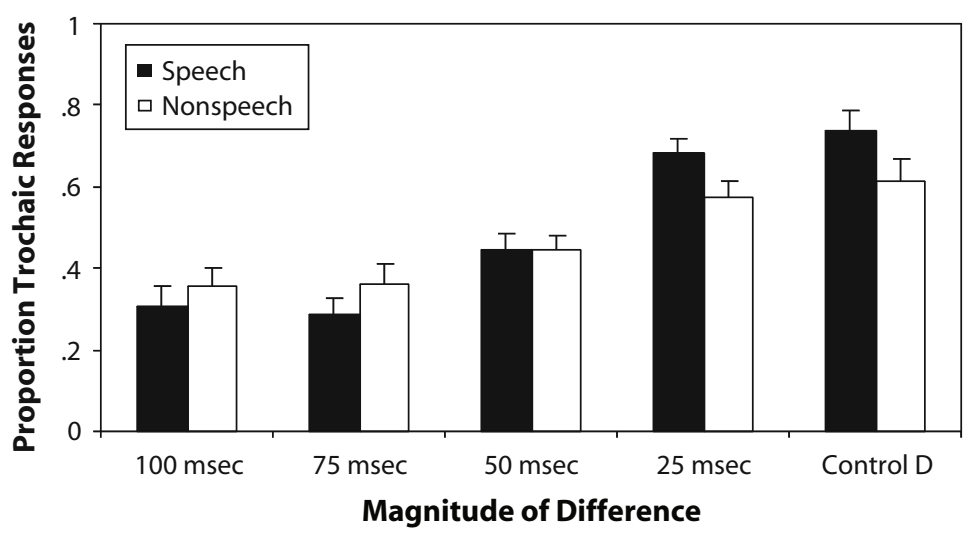

Figure 1. Perceived rhythm of duration-varying sequences. The difference in duration between alternating elements is given on the $x$-axis. For Control $\mathrm{D}$, there was no difference between the alternating sounds. Error bars represent the standard error of the mean.

\section{Results}

In this and the following experiment, the participants described the speech and nonspeech stimuli in very different ways. In the speech conditions, the stimuli were judged to be speech-like and were often perceived as nonsense words containing the consonant $/ \mathrm{g} /$. The participants in the nonspeech conditions generally heard the square wave segments as computer-generated beeps or video game sounds.

ANOVAs were performed in order to examine the within-subjects effects of magnitude of difference (i.e., the amount of absolute difference) between alternating segments and the between-subjects effect of stimulus type (i.e., synthetic speech vs. nonspeech) on the proportion of trochaic responses. Because the order of onset of the initial segment was not a variable of interest, each analysis was conducted with the data collapsed over the two order conditions.

Duration. The results for the duration-varying conditions are presented in Figure 1. There was a significant effect of magnitude of difference on rhythmic grouping $[F(4,184)=30.68, p<.001]$, but there was not a significant effect of stimulus type ( $p=.516)$ or an interaction between the two variables. Individual comparisons showed that only the sequences varying by $50 \mathrm{msec}$ or more were grouped more iambically than was the control stimulus (Control D) that was presented in the same context as the rest of the duration-varying sequences (all $p$ values $<.001)$. Increasing the duration difference from 75 to $100 \mathrm{msec}$ did not significantly increase the proportion of iambic grouping $(p=.811)$.

Intensity. Figure 2 shows the results for the intensityvarying conditions. As the magnitude of absolute difference between the alternating stimuli increased, so did the tendency toward trochaic grouping $[F(4,184)=7.76, p<$ $.001]$. This same pattern was observed for both the speech and the nonspeech conditions, with no significant difference between the two $(p=.371)$. Again, the two-way interaction of magnitude of difference and stimulus type was not significant $(p=.920)$. When the intensity dif-

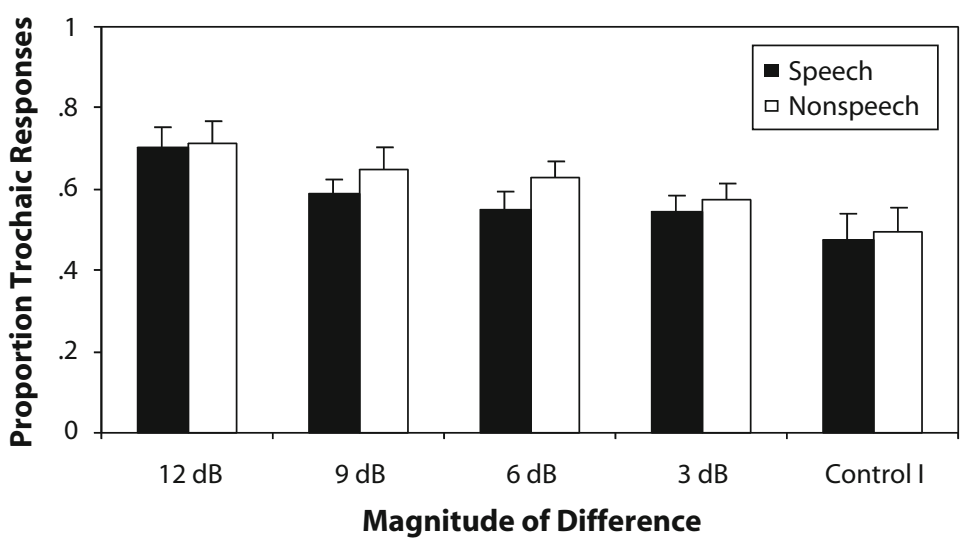

Figure 2. Perceived rhythm of intensity-varying sequences. The difference in intensity between alternating elements is given on the $x$-axis. For Control I, there was no difference between the alternating sounds. Error bars represent the standard error of the mean. 


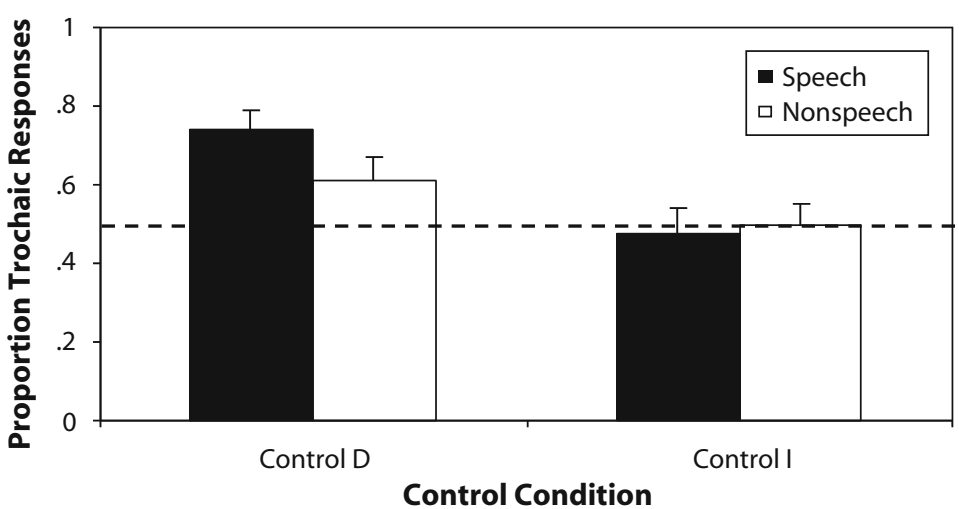

Figure 3. Perceived rhythm of the control sequences when presented in the context of duration-varying (Control D) and intensity-varying (Control I) sequences. Error bars represent the standard error of the mean. A proportion of trochaic judgments of .5 is indicated by a dashed line.

ference exceeded $3 \mathrm{~dB}$, intensity-varying sequences were grouped more trochaically than was the control sequence (Control I; all $p$ values $<.05$ )

Control sequences. An ANOVA revealed that context had a significant effect on the grouping of the control sequences $[F(1,92)=11.216, p<.005]$; the control sequence was perceived to have a trochaic rhythm more often when it was presented in the context of the durationvarying stimuli (i.e., Control D) than when the same stimulus was presented in the context of the intensity-varying stimuli (i.e., Control I). Figure 3 shows that Control D was perceived as having a trochaic rhythm at a proportion greater than $.5[t(27)=4.589$, two-tailed $p<.001]$, whereas Control I did not consistently elicit either iambic or trochaic grouping $(p=.758)$. There was no main effect of stimulus type $(p=.603)$, nor did stimulus type interact with context condition $(p=.307)$.

\section{Discussion}

The results of Experiment 1 verified Woodrow's (1909) findings and generally supported the iambic/trochaic law (Hayes, 1995). Variation in duration causes alternating sequences to be grouped with final prominence, whereas variation in intensity results in the perception of groupinitial prominence. In order for these characteristic rhythmic groupings to emerge, however, the magnitude of difference between two alternating segments must have surpassed some threshold value. Generally, durationvarying sequences were perceived more iambically than was Control D if the magnitude of difference was $50 \mathrm{msec}$ or more, whereas sequences with intensity differences of $6 \mathrm{~dB}$ were consistently perceived more trochaically than was Control I.

An unexpected finding of the present study was that the perceived rhythm of the control sequence varied as a function of context. In the context of intensity-varying sequences, the control sequence (Control I) was perceived either as lacking alternating prominence or as being slightly trochaic. In the context of the duration-varying sequences, the control sequence (Control D) was judged as clearly trochaic. This context effect appears to result from a kind of perceptual contrast. Sequences with equallength elements tend to sound trochaic when they appear in the context of sequences that (owing to variation in certain physical parameters) sound iambic.

The results of Experiment 1 suggest that rhythmic grouping is similar for both kind of stimuli and may, thus, depend on general auditory biases. There is, however, another possible interpretation of the finding that speech and nonspeech elicit similar perceptual grouping patternsnamely, that experience with the rhythmic structure of English caused the English-speaking listeners to perceive both the speech and the nonspeech stimuli through an "English" linguistic filter. There is some evidence that linguistic experience may affect the identification (Bent, Bradlow, \& Wright, 2003) and discrimination (Hay, 2005) of some nonspeech sounds, and it is possible that the effects found in the present experiment resulted from language-specific perceptual-grouping strategies, and not from general auditory processing. In Experiment 2, we addressed this possibility.

\section{EXPERIMENT 2}

Previous research suggests that some speech segmentation strategies are language dependent and are based on the native language's rhythmic characteristics (Cutler, 1994). Jakobson, Fant, and Halle (1967) reported (apparently on the basis of informal observations) that knocks produced at even intervals, with every third one louder, are grouped in accordance with the characteristic stress patterns of the listener's language. For example, Czech listeners heard a pause just before the louder knock, whereas Polish listeners heard a pause after the knock following the louder knock. Because, to our knowledge, these observations have never been replicated, it remains an open question as to how linguistic experience shapes listeners' perception of prominence-based rhythm. Experiment 2 was designed to address this question. ${ }^{3}$

In this experiment, half the participants were monolingual English-speaking listeners, and the other half were 
monolingual French-speaking listeners. These listeners performed the same rhythmic grouping tasks on speech and nonspeech stimuli as those in Experiment 2.

In both English and French, rhythm is based on an alternation of more prominent and less prominent syllables (Grammont, 1946; Wenk \& Wioland, 1982), but there are important differences between the two languages. In English, lexical stress is easily detectable, and the majority of bisyllabic words are trochaic. The most important cue for English stress is $f 0$ contour, followed by duration and intensity (Fry, 1955). These cues are highly correlated, and stressed syllables tend to lead the group in which they occur, except when the stressed syllables are very long (Hayes, 1995). French, on the other hand, lacks lexical stress but has phrase-final prominence (Dell, 1984; Tranel, 1987). Successive syllables in a phrase are very similar in duration, $f 0$, and intensity, except for the last syllable, which is, on average, higher in $f 0$, slightly less intense, and much longer than the preceding ones (Delattre, 1966). Coupled with the lower intensity, the combination of an increase in $f 0$ and a large increase in duration on the final syllable gives French phrases terminal prominence and makes them more iambic sounding than English phrases. Owing to the differences in stress assignment between English and French, these two languages are good candidates for a cross-linguistic comparison of rhythmic grouping.

\section{Method}

Listeners. A total of 48 listeners participated in Experiment 3. Twenty-four were native English-speaking listeners, and 24 were native French-speaking listeners. Half of each language group participated in the speech condition, and half in the nonspeech condition. French-speaking listeners were recruited from signs posted at the Laboratoire de Psychologie Expérimentale in Paris and were paid for their participation. These listeners were tested individually at the same location. All the English-speaking listeners were recruited from the introductory psychology participant pool at the University of Texas at Austin and were given credit toward partial fulfillment of course requirements. These listeners were run in groups of 1-4. All the listeners reported being monolingual and having normal hearing.

Stimuli. All the stimuli were identical to those described in Experiment 1, except that a slightly improved masking technique was used during the onset of each sequence. First, the signal-tonoise ratio was decreased from $-5.4 \mathrm{~dB}$ in the first experiment to $-16.9 \mathrm{~dB}$ in this experiment. Second, the onset of the first sound in each sequence was roved between 0 and $200 \mathrm{msec}$, in 50-msec steps, relative to the onset of the masking noise. On half the trials, the first stimulus was the stronger sound. This resulted in 10 sequences at each level of absolute difference between alternating stimuli.

Procedure. All oral interactions with the participants and all written instructions were in their native language. The participants were seated in front of a computer (English, Gateway 2000 desktop; French, Dell Inspiron 8000 laptop), on which the tasks were administered. All the stimuli were randomized and presented using an in-house experimental design program. Stimuli were played through Beyer dynamic DT100 headphones. English-speaking listeners were run in a double-walled sound-attenuated chamber. French-speaking listeners were run in a quiet room. Excluding practice trials, all the listeners heard a total of 50 duration-varying and 50 intensityvarying stimulus sequences. All other procedures were identical to those described in Experiment 1.

\section{Results}

Duration. There was a significant effect of magnitude of difference $[F(4,176)=8.28, p<.001]$ : As the size of the difference increased, so did the tendency toward iambic grouping (see Figure 4). There were no main effects of language $(p=.989)$ or of stimulus type $(p=.448)$ and no interaction between magnitude of difference and language ( $p=.611)$, between magnitude of difference and stimulus type ( $p=.958)$, between language and stimulus type $(p=.094)$, or between all three of these variables $(p=.631)$. These results suggest that the effect of magnitude of differences is similar for English- and Frenchspeaking listeners and for speech and nonspeech stimuli.

However, it should be noted that the effect of magnitude of difference was more consistent for the English group than for the French group. When analyses were performed separately for the two language groups, there were still significant main effects of magnitude of difference [English, $F(4,88)=4.37, p<.005$; French, $F(4,88)=$ $2.60, p<.05]$. But when the analyses were performed separately for the speech and the nonspeech conditions, the effect of magnitude of difference remained significant for the English group [speech, $F(4,44)=3.19, p<$ .025 ; nonspeech, $F(4,44)=4.37, p<.005]$, but not for the French group (speech, $p=.355$; nonspeech, $p=$ .076). Thus, for the French-speaking listeners, the effect of magnitude of difference was significant only when the data were collapsed across the speech and nonspeech conditions.

Intensity. As the magnitude of difference increased, so did the tendency toward trochaic grouping $[F(4,176)=$ $14.50, p<.001$; see Figure 5]. No significant effects were observed for language $(p=.900)$ or stimulus type ( $p=$ .340 ), and there was no interaction between magnitude of difference and language ( $p=.702)$, between magnitude of difference and stimulus type $(p=.505)$, or between all three of these variables $(p=.476)$.

When the two language groups were analyzed separately, the effect of magnitude of difference remained highly significant [English, $F(4,88)=9.35, p<.001$; French, $F(4,88)=6.00, p<.001]$. For the English group, significant effects of magnitude of difference held for both the speech $[F(4,44)=5.36, p<.001]$ and the nonspeech $[F(4,44)=4.48, p<.005]$ conditions. For the French group, the magnitude-of-difference effect was significant for the speech condition $[F(4,44)=5.62, p<$ $.001]$, but not for the nonspeech condition ( $p=.305)$. Thus, as in the case of duration differences, intensity differences yielded more consistent rhythmic-grouping tendencies among the English-speaking than among the French-speaking listeners.

\section{Discussion}

The results of Experiment 2 lend further support to the iambic/trochaic law and show that it applies to groups of listeners with differing linguistic experience. For both English- and French-speaking listeners, there was a tendency to judge sequences varying in duration as having 
iambic rhythm and sequences varying in intensity as having trochaic rhythm. These results suggest that the similarities in rhythmic grouping of speech and nonspeech, seen in Experiment 1, were not simply the result of linguistic experience with English. Instead, these results support the view that the iambic/trochaic law reflects general auditory biases. It should be noted, however, that although there were no significant main effects of language or significant interactions in which language was a factor, the rhythmic grouping effects were generally more consistent for the English group than for the French group.

\section{GENERAL DISCUSSION}

The present experiments were intended to (1) explore how certain acoustic parameters of alternating sound sequences affect rhythmic grouping and (2) examine whether rhythmic grouping is affected by linguistic experience or whether it is mainly a function of general auditory mechanisms. Specifically, we tested the iambic/ trochaic law (Hayes, 1995), which makes claims regarding the perceptual grouping of sounds.

Experiment 1 was intended to replicate previous work, but it was the first experiment of this kind to use both strictly controlled stimulus parameters and stimulus- onset-masking techniques. As is predicted by the iambic/ trochaic law (Hayes, 1995), elements contrasting in duration formed groupings with final prominence, and those contrasting in intensity formed groupings with initial prominence.

If language experience plays a role in rhythmic grouping, differences might be expected in the judgments for speech and nonspeech sequences. Across both experiments, there were no main effects or interactions involving stimulus type. In general, then, results for the speech and the nonspeech conditions patterned in similar ways, despite the fact that all the listeners reported perceiving the synthetic speech stimuli as speech-like, whereas none reported hearing the nonspeech stimuli as speech-like.

The main objectives of Experiment 2 were to replicate Experiment 1 with a better onset-masking procedure and to further examine how linguistic experience shapes listeners' perception of rhythm. The magnitude of difference among the alternating sequences had significant effects in both the duration- and the intensity-varying conditions. Native-speaking listeners of both English and French tended to group stimuli with large durational differences iambically and stimuli with small or zero durational differences trochaically. There was no significant main effect of language and no significant interactions involving

(A) Speech

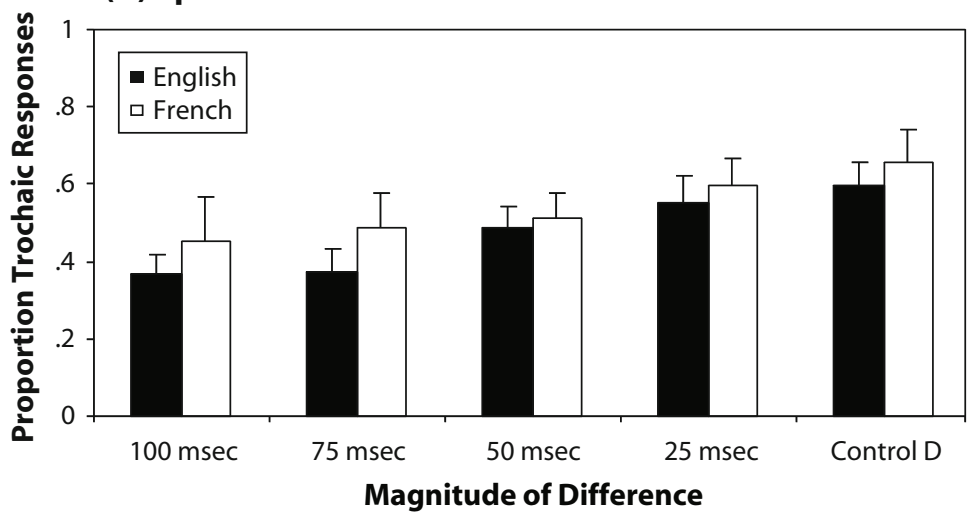

(B) Nonspeech

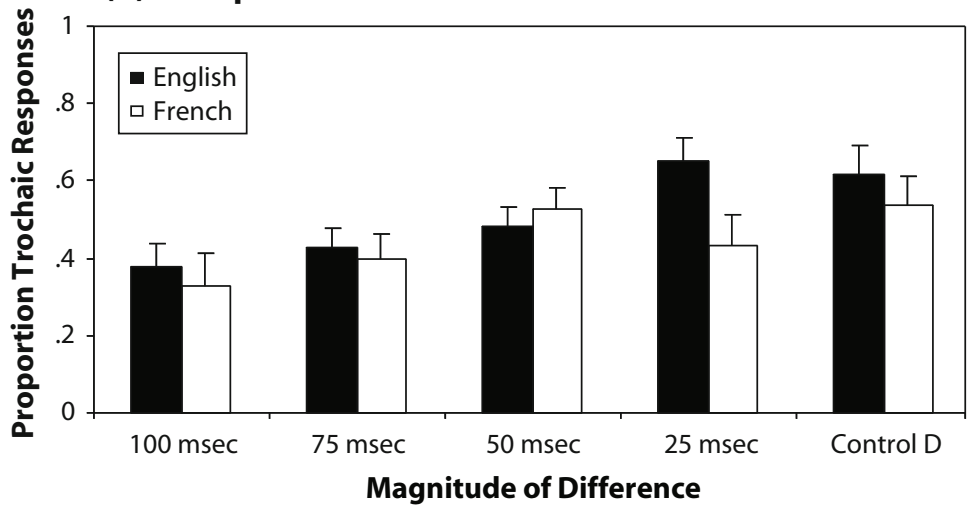

Figure 4. Perceived rhythm of duration-varying sequences by English- and French-speaking listeners in (A) speech and (B) nonspeech conditions. The difference in duration between alternating elements is given on the $\boldsymbol{x}$-axis. Error bars represent the standard error of the mean. 


\section{(A) Speech}

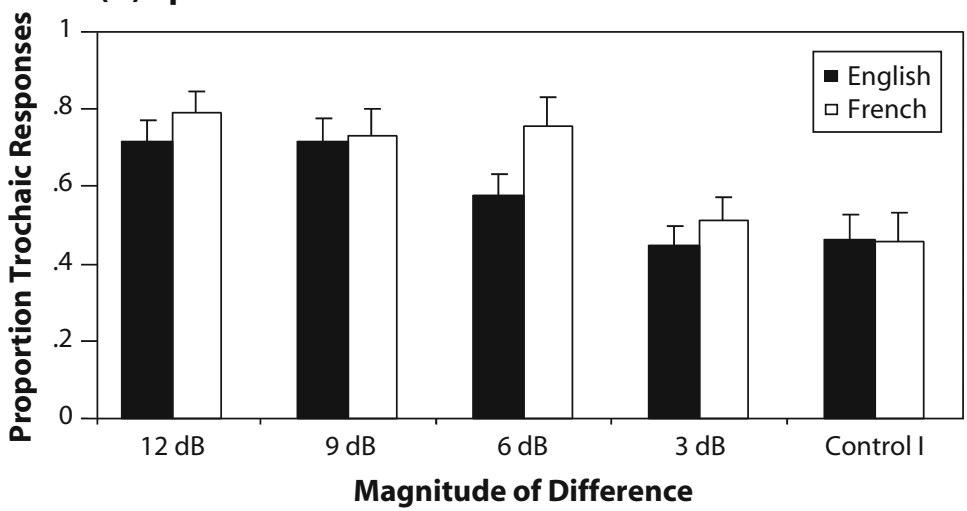

(B) Nonspeech

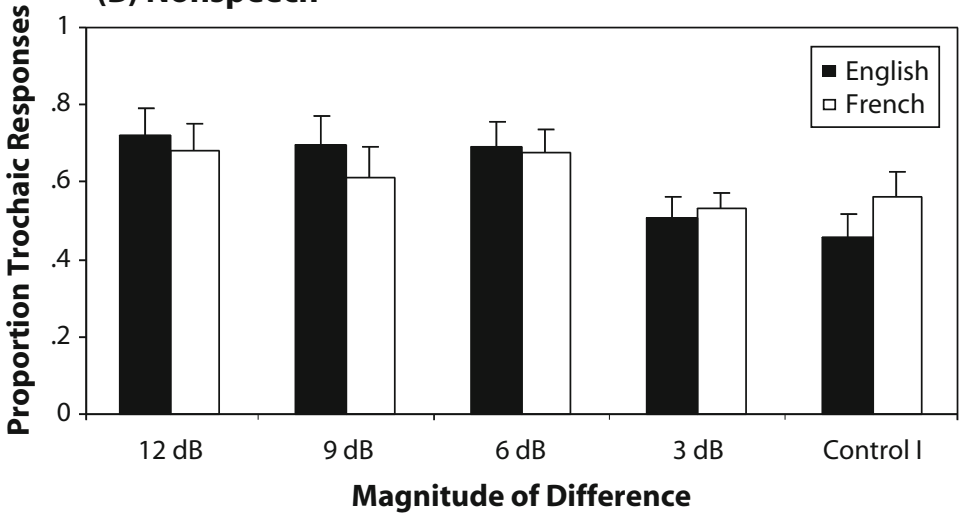

Figure 5. Perceived rhythm of intensity-varying sequences by English- and French-speaking listeners in (A) speech and (B) nonspeech conditions. The difference in intensity between alternating elements is given on the $x$-axis. Error bars represent the standard error of the mean.

language. These findings suggest that the iambic/trochaic law has some cross-language validity.

A key question addressed in the present study is whether rhythmic grouping of sounds arises from general auditory mechanisms independently of language or whether it, instead, depends on linguistic experience (e.g., on exposure to language-specific ways of implementing prominence relations within utterances). Overall, the results tended to favor a general auditory account of rhythm perception. Despite a few differences between the speech and the nonspeech conditions for the French-speaking listeners, rhythmic judgments for the square wave segments were broadly similar in pattern to those for the $/ \mathrm{ga} /$ syllables.

However, it is possible that native language prosody affects rhythm perception for nonspeech sounds, as well as for speech sounds. Recall that Jakobson et al. (1967) made just this claim, reporting anecdotally that nonspeech sequences are grouped in accordance with the characteristic stress patterns of the listener's language. These observations have not, to our knowledge, been replicated; accordingly, a main aim of Experiment 2 was to investigate possible native language effects on perceived rhythm.

The results for both the English and the French groups were compatible with the iambic/trochaic law. In both cases, increases in durational differences among alternat- ing stimuli produced more iambic judgments, whereas increases in intensity differences among stimuli yielded more trochaic judgments. There was no significant main effect of language and no significant interactions involving language. Given the clear prosodic differences between English and French (e.g., English tends to have initial-syllable prominence, whereas French has [phrase] final-syllable prominence), the similarity of results between the two language groups offers support for the view that rhythm perception depends largely on general auditory, rather than specifically linguistic, mechanisms.

However, there are two reasons to be tentative in drawing the conclusion above. First, our experimental design differed considerably from that described by Jakobson et al. (1967), so their conclusions about the influence of native language on rhythm perception cannot be dismissed. Clearly, a more exact replication of their design is needed to resolve this issue. Second, although language was not a significant variable in the present study, it is nevertheless true that the iambic/trochaic law was less consistently demonstrated for the French group than for the English group. This suggests that there may have been some languagespecific influences on rhythmic judgments.

A possible function of perceived rhythm in spoken language is to facilitate the segmentation of utterances 
into word length and, perhaps, phrase length units. Cutler (1994) suggested that infants exploit natural rhythmic cues to segment utterances and that rhythm-based segmentation strategies learned early in life extend into adulthood. She and her colleagues reported, for example, that Englishspeaking listeners tend to segment utterances at the onsets of stressed (strong) syllables (Cutler \& Butterfield, 1992; Cutler \& Norris, 1988). These findings and others (e.g., Echols et al., 1997; Thiessen \& Saffran, 2003) raise the possibility that the iambic/trochaic law plays a role in the perceptual segmentation of utterances into smaller linguistic units. This role may be especially important for infant listeners faced with the challenge of learning to extract word length units from the continuous stream of speech.

If the iambic/trochaic law reflects general auditory biases present even in early infancy, it should yield an initial parsing of utterances into groups of syllables. Of course, for this parsing to facilitate word extraction, there must exist a rough correspondence between perceived syllable groups and words of the language. A necessary, but not sufficient, condition for such a correspondence to be demonstrated is that words should tend to have either initial or final syllable stress patterns (corresponding to trochaic or iambic rhythm, respectively). A typological survey (Hyman, 1977, as cited in Laver, 1994) of lexical stress patterns in 444 languages suggests that this condition is commonly satisfied. Over two thirds of the languages in the survey had predominately fixed lexical stress patterns. (Most of the rest had variable stress patterns, and a few had no lexical stress.) Of the languages with predominately fixed stress patterns, the largest subgroup (114 languages) had initial syllable stress, and the second largest subgroup (97 languages) had final syllable stress. Moreover, languages with variable stress patterns (e.g., English) may have strong tendencies to favor initial or final stress patterns, and even languages with no lexical stress (e.g., French) may exhibit initial or final prominence at the phrase level.

However, in order for the iambic/trochaic law to yield rhythmic parsing appropriate for word or phrase extraction, another condition must be met: The physical correlates of stressed or otherwise prominent syllables must be conducive to particular rhythmic outcomes - namely, trochaic or iambic syllable groupings. Thus, if a trochaic grouping is to be perceived, there must be strong variation in intensity between syllables and relatively little variation in duration. On the other hand, if an iambic grouping is to be perceived, most of the variation between syllables must be in duration, rather than in intensity. Do the normal physical correlates of stress or prominence pattern in these ways?

Consider, first, the case of French. As was noted earlier, French phrase-final syllables have a higher pitch and a slightly lower intensity, coupled with a large increase in duration (Delattre, 1966). The results of the present study suggest that the intensity and durational correlates should give rise to an iambic (or more generally, final-syllableprominent) rhythmic grouping, as is, in fact, observed. Accordingly, it is reasonable to conclude that the iambic/ trochaic law yields perceptual groupings consistent with phrasal units in spoken French, thereby facilitating a linguistically relevant parsing of utterances by listeners.

More generally, it is known that final-syllable lengthening occurs in most, if not all, languages (Klatt, 1975, 1976; Lindblom \& Rapp, 1973; Oller, 1973) and that final lengthening actually refers to a nested set of lengthening effects. In phrase-nonfinal environments, word-final syllables tend to be somewhat longer than word-initial and word-medial syllables (Klatt, 1975). Word-final lengthening is considerably greater in a phrase-final position and even greater in a sentence-final position (Lindblom \& Rapp, 1973). In these cases, the effect of the iambic/trochaic law may be to accentuate perceptually the demarcation of linguistic units at several levels of analysis.

Next, consider the case of English. Unlike French, English is a language with lexical stress, and as is true in most such languages, stressed syllables tend to be longer and louder and to have higher, more dynamic pitch contours than do unstressed syllables, all else being equal (Lehiste, 1970). In light of the present results, these correlates (in particular, intensity and duration) do not appear to be conducive to a clear parsing based on either a trochaic or an iambic grouping of syllables, because the effect of the durational correlate would tend to cancel out the effect of the intensity correlate. Thus, although these correlates may be assumed to contribute to the perceived prominence of stressed syllables, they do not yield a consistent grouping effect, at least according to the present results. Therefore, it seems questionable that the auditory biases implied by the iambic/trochaic law actually facilitate the parsing of English utterances into word length units. Further doubts on this matter are raised by the finding that whereas English words tend to have a trochaic stress pattern, duration and pitch contour cues appear to have greater weight in judgments of English word stress patterns than do intensity cues (Fry, 1955, 1958). This seems counter to what might be expected on the basis of the iambic/trochaic law.

An interesting question for future research is whether, in general, languages with word-initial stress differ, in their deployment of stress cues, from languages with word-final stress. Despite the English example, it is possible that other languages with word-initial stress tend to place greater weight on intensity cues and less weight on durational cues than do languages with word-final stress. Such a finding would suggest that languages do, in fact, exploit the auditory effects of the iambic/trochaic law to enhance the segmentation of utterances into words.

\section{AUTHOR NOTE}

This work was supported by Grants R01 DC00427-13, -14, and -15 from the National Institutes of Health, National Institute on Deafness and Other Communication Disorders, to the second author and by a Liberal Arts Graduate Research Fellowship from the University of Texas at Austin to the first author. Special thanks to Juan Segui and Ludovic Ferrand of the CNRS and Université René Descartes, Laboratoire de Psychologie Expérimentale, Paris, for providing facilities for conducting the French portion of the study. The authors also thank Catharine Echols for her comments on earlier drafts of the manuscript. Correspondence concerning this article should be addressed to J. S. F. Hay, Department of Psychology, University of Wisconsin, 1202 West Johnson Street, Madison, WI 53706 (e-mail: hay@waisman.wisc.edu). 


\section{REFERENCES}

Beckman, M. E. (1986). Stress and non-stress accent (Netherlands Phonetic Archives 7). Dordrecht: Foris.

Benguerel, A.-P., \& D'Arcy, J. (1986). Time-warping and the perception of rhythm in speech. Journal of Phonetics, 14, 231-246.

Bent, T., Bradlow, A. R., \& Wright, B. A. (2003). The influence of linguistic experience on pitch perception in speech and nonspeech sounds [Abstract]. Journal of the Acoustical Society of America, 113, 2256.

Bolinger, D. L. (1958). A theory of pitch accent in English. Word, 14, 109-149.

Crystal, T. H., \& House, A. S. (1990). Articulation rate and the duration of syllables and stress groups in connected speech. Journal of the Acoustical Society of America, 88, 101-112.

CUTLER, A. (1994). Segmentation problems, rhythmic solutions. Lingua, 92, 81-104

CUTLER, A., \& Butterfield, S. (1992). Rhythmic cues to speech segmentation: Evidence from juncture misperception. Journal of Memory \& Language, 31, 218-236.

CUTler, A., Mehler, J., Norris, D., \& Segui, J. (1986). The syllable's differing role in the segmentation of French and English. Journal of Memory \& Language, 25, 385-400.

CUTLER, A., \& NorRIS, D. (1988). The role of strong syllables in segmentation for lexical access. Journal of Experimental Psychology: Human Perception \& Performance, 14, 113-121.

DaRWIN, C. J., \& Donovan, A. (1980). Perceptual studies of speech rhythm: Isochrony and intonation. In J. C. Simon (Ed.), Spoken language generation and understanding (pp. 77-85). Dordrecht: Reidel.

Delattre, P. (1965). Comparing the phonetic features of English, French, German and Spanish: An interim report. Heidelberg: Groos.

Delattre, P. (1966). A comparison of syllable length conditioning among languages. International Review of Applied Linguistics in Language Teaching, 4, 183-198.

Dell, F. (1984). L'accentuation dans les phrases français. In F. Dell, D. Hirst, \& J.-R. Vergnaud (Eds.), Forme sonore du langage: Structure des représentations en phonologie (pp. 65-122). Paris: Hermann.

Dell, F., \& Vergnaud, J.-R. (1984). Les développements récents en phonologie: Quelques idées centrales. In F. Dell, D. Hirst, \& J.-R. Vergnaud (Eds.), Forme sonore du langage: Structure des représentations en phonologie (pp. 1-42). Paris: Hermann.

Donovan, A., \& Darwin, C. J. (1979). The perceived rhythm of speech. In Proceedings of the Ninth International Congress of Phonetic Sciences (Vol. 2, pp. 268-274). Copenhagen: Institute of Phonetics.

Echols, C. H., Crowhurst, M. J., \& Childers, J. B. (1997). The perception of rhythmic units in speech by infants and adults. Journal of Memory \& Language, 36, 202-225.

FRAISSE, P. (1974). Psychologie du rythme. Paris: Presses Universitaires de France.

Fraisse, P. (1982). Rhythm and timing. In D. Deutsch (Ed.), The psychology of music (pp. 149-180). New York: Academic Press.

FRY, D. B. (1955). Duration and intensity as physical correlates of linguistic stress. Journal of the Acoustical Society of America, 27, $765-768$.

FRY, D. B. (1958). Experiments in the perception of stress. Language \& Speech, 1, 126-152.

Grammont, M. (1946). Traité pratique de prononciation française. Paris: Librairie Delagrave.

HAY, J. (2005). How auditory discontinuities and linguistic experience affect the perception of speech and non-speech in English-and Spanish-speaking listeners. Unpublished doctoral dissertation, University of Texas, Austin.

HAYES, B. (1995). The rhythmic basis of the foot inventory. In B. Hayes (Ed.), Metrical stress theory: Principles and case studies (pp. 79-85). Chicago: University of Chicago Press.

Hyman, L. (1977). On the nature of linguistic stress. In L. Hyman (Ed.), Studies in stress and accent (Occasional Papers in Linguistics 4, pp. 37-82). Los Angeles: University of Southern California, Department of Linguistics.

Jakobson, R., Fant, C. G. M., \& Halle, M. (1967). Preliminaries to speech analysis: The distinctive features and their correlates. Cambridge, MA: MIT Press.
KLATT, D. H. (1975). Vowel lengthening is syntactically determined in a connected discourse. Journal of Phonetics, 3, 129-140.

KLATT, D. H. (1976). Linguistic uses of segmental duration in English: Acoustic and perceptual evidence. Journal of the Acoustical Society of America, 59, 1208-1221.

KLATT, D. H., \& KlatT, L. C. (1990). Analysis, synthesis, and perception of voice quality variations among female and male talkers. Journal of the Acoustical Society of America, 87, 820-857.

LAVER, J. (1994). Principles of phonetics. Cambridge: Cambridge University Press.

Lehiste, I. (1970). Suprasegmentals. Cambridge, MA: MIT Press.

Lehiste, I. (1977). Isochrony reconsidered. Journal of Phonetics, 5, 253-263.

LindBlom, B., \& RAPP, K. (1973). Some temporal regularities of spoken Swedish (Pub. 21). Stockholm: University of Stockholm, Institute of Linguistics.

Mattys, S. L., JusczyK, P. W., Luce, P. A., \& Morgan, J. L. (1999). Phonotactic and prosodic effects on word segmentation in infants. Cognitive Psychology, 38, 465-494.

Mehler, J., Dommergues, J.-Y., Frauenfelder, U., \& Segui, J. (1981). The syllable's role in speech segmentation. Journal of Verbal Learning \& Verbal Behavior, 20, 298-305.

OLLER, D. K. (1973). The effect of position in utterance on speech segment duration in English. Journal of the Acoustical Society of America, 54, 1235-1247.

Otake, T., Hatano, G., Cutler, A., \& Mehler, J. (1993). Mora or syllable? Speech segmentation in Japanese. Journal of Memory \& Language, 32, 258-278.

PIERREHUMBERT, J. (1980). The phonology and phonetics of English intonation. Doctoral dissertation, MIT. [Distributed by the Indiana University Linguistics Club, Bloomington]

RICE, C. C. (1992). Binarity and ternarity in metrical theory: Parametric extensions. Unpublished doctoral dissertation, University of Texas, Austin.

Saffran, J. R., Newport, E. L., \& Aslin, R. N. (1996). Word segmentation: The role of distributional cues. Journal of Memory \& Language, 35, 606-621.

Schwartz, R. G., Petinou, K., Goffman, L., Lazowski, G., \& CarTUSCIELLO, C. (1996). Young children's production of syllable stress: An acoustic analysis. Journal of the Acoustical Society of America, 99, 3192-3200.

ThiEsSEN, E. D., \& SAFFran, J. R. (2003). When cues collide: Use of stress and statistical cues to word boundaries by 7- to 9-month-old infants. Developmental Psychology, 39, 706-716.

Tranel, B. (1987). The sounds of French: An introduction. Cambridge: Cambridge University Press.

Vroomen, J., Tuomainen, J., \& de Gelder, B. (1998). The roles of word stress and vowel harmony in speech segmentation. Journal of Memory \& Language, 38, 133-149.

WENK, B. J., \& WiOLAND, F. (1982). Is French really syllable-timed? Journal of Phonetics, 10, 193-216.

WOODROW, H. (1909). A quantitative study of rhythm: The effect of variations in intensity, rate, and duration. Archives of Psychology, 14, $1-66$.

Woodrow, H. (1951). Time perception. In S. S. Stevens (Ed.), Handbook of experimental psychology (pp. 1224-1236). New York: Wiley.

\section{NOTES}

1. Because maintaining a constant interstimulus interval across sequences was considered desirable, variation in stimulus duration inevitably led to changes in sequence tempo.

2. Since the stimuli in the control sequence were identical, there was a single order of onset for the control stimuli.

3. See, however, Benguerel and D'Arcy (1986) for a demonstration that rhythmical judgments may not be affected by either linguistic experience or speech mode (speech vs. nonspeech).

(Manuscript received August 22, 2005; revision accepted for publication March 23, 2006.) 